\title{
First Year Medical Student's Viewpoint Regarding Qualities of an Excellent Teacher
}

\author{
Mamoon Akbar Qureshi ${ }^{*}$ \\ Ambreen Ahsan Shah** \\ Mohammad Ali* \\ Kamila Iftikhar*** \\ Muhammad Atif**** \\ Ayub Sabir***** \\ Imran Anwar Khan******
}

\begin{abstract}
In the academia, the qualities of excellent teacher are related to personal traits, effective teaching technique, and interpersonal communication of teacher. A qualitative research was conducted to identify the characteristics of a good clinical teacher as perceived by first year medical students at Allama Iqbal Medical College, Lahore, Pakistan from May, 2015 to July, 2015. Twenty five medical students were asked to express their opinion freely about qualities of teacher whom they think qualifies him/her as an excellent teacher and what specifically makes his/her lectures so effective according to their perceptions. Phenomenological approach was used to investigate medical students' experiences and their interpretations of the excellent teacher. Several key analytic strategies were used such as 'Coding', for both categorizing qualitative data and describing the connotation and details of these categories. Two major themes that an excellent teacher should possess were personal qualities and presentation skills from which 15 sub-themes were identified .The study concluded that first year medical students think that an excellent teacher should not only possess personal characteristics and qualities like good moral character, empathy and

\footnotetext{
* Lecturer, Department of Community Medicine Allama Iqbal medical College, Lahore Pakistan

** Department of Social and Cultural Studies, University of the Punjab Lahore Pakistan. *** Senior medical officer, Fellow M.D. Developmental pediatrics, Children Hospital and IAHS, Lahore

**** Lecturer, Department of Community Medicine, Lahore Medical \& Dental College, Lahore.

****** Medical officer, DHQ Hospital, Okara

****** House 128-III- B, Model Town, Lahore
} 
sympathy but he should also exhibit excellent skills in lecture delivery, ability to organize lectures and its contents.

Key Words: Teacher, qualities, Medical students, characteristics.

\section{Introduction}

Studies on medical student's perceptions about their teachers, in developing countries are scarce. The environment of local universities is very challenging due to the increasing demands, standards, and expectations of the parents, students and the Government. The teachers are overwhelmed with multiple roles and tasks such as conducting research for promotion purposes, attending seminars, project presentations and engaging in students' and community related activities especially in medical education (Emery et al, 2013). Subsequently, the teachers have the tendency to experience negative emotions such as tension, hostility, depression, anger, nervousness and frustration (Iskendar et al, 2009 \& Ismail et al, 2009) and this can affect his teaching or delivery of knowledge to the students .The lectures are the main mode of teaching in medical education as in other disciplines, that is not only widely implied from the start of medical education but also continued in many areas during medical career such as continuing medical education. (Nelson et al, 2003).

According to Henzi, et al (2005) students are the most affected group by their education, but often they feel that they have the least amount of input for change regarding teaching methodologies. (Henzi et al., 2005). Studies that look at student's perceptions regarding their education attempt to struggle with the notion in this statement by taking into account, students' needs and wants in order to improve the educational system are always welcomed.

One of the key questions is that what is the role of the teacher in the context of new developments taking place in medical education and what are the perceptions of medical students regarding a good teacher? There has been little sustained analysis of the role of the teacher. In general, usually teachers are preoccupied with the details of curriculum planning, with the content of the teaching programme and with the range of educational strategies adopted and failed to take a broader view of the role of the teacher in these tasks, especially from student's perspective. (Squires, 1999). 
First Year Medical Student's Viewpoint Regarding Qualities of An Excellent ...

This study attempts to analyze qualitatively, the role of medical teacher from first year medical students' perspective as what they think about the qualities and characteristics of an excellent teacher.

\section{Literature Review}

Thinking of an excellent teacher, Bernhard Siegfried Albinus, an 18th Century anatomy professor at Leiden, gained such distinction that his lectures often drew crowds of "fashionable folk", like those portrayed in this engraving. While times have changed and the public no longer wanders through our lecture halls looking for entertainment, the lecture remains as a core teaching strategy in medical schools. It is estimated that the average medical student might sit through hundreds of hours of lectures by the end of their medical career (Sadwink, 2012). A 2002-03 review of feedback from students regarding the quality of lectures in the first and second years of the medical school curriculum revealed that the average performance was 3.0 on a five point scale. Therefore, at least from our students' point of view, there is room for improvement in the quality of our lectures (Sadwink, 2012).

A study among medical and dental students, (Jahangiri and Mucciolo, 2008) report that the top priorities in terms of learning were content organization, content development ,content design ,expertise, and speaking style from student's perspective.

However, in a resource deficient environment, such as in public medical schools of developing countries ,Henzi's original statement is amplified as medical students face additional challenges in receiving a quality education. By definition, a limited resource setting is one in which there is difficulty in meeting the basic needs of an environment, whatever this may be in terms of experienced human resource, up to date class rooms, teaching aids and space. Although the senior faculty in public medical schools in Pakistan is experienced but its physical infrastructure is ramshackle and it lacks sufficient audio-visual equipment, labs, lecture halls, and clinical space as now the gender composition and number of students are almost doubled than it was 10 years back in same space in campus.

Many studies have also found that the expectations of students vary according to the learning environment and resources available to them (Redding \& Walberg, 2012; Maheuxet al., 2000; Nahar, 2010). Redding discusses the student-teacher relationship, and the positive effects of teacher enthusiasm on students' motivation and performance in 
a rural setting (Redding, 2012). Maheux's eloquently elaborates the importance of humanism in the learning environment in both traditional and innovative medical schools (Maheux, 2000).

March and Roche (1993) examined student's evaluation of teaching effectiveness as a mean of enhancing university teaching. Rayan and Harrison (1995) investigated how students weighed various teaching methodologies adopted by teachers in their overall evaluation of teaching effectiveness.

Axelord (2008) has found that student's perceived that an effective teacher should have seven qualities like accessibility and approachability, fairness, open mindedness, mastery of subject and delivery, enthusiasm, humor and knowledge and inspiration imparted.

Ramsden (1992) identifies six key principles of effective teaching in Higher Education from students' point of view as follow: The teachers should have an interest in the subject and be able to explain it to others, there should be a concern and respect for students and student learning, appropriate assessment and feedback should be provided, there should be clear goals and intellectual challenge, learners should have independence, control and active engagement. Teachers should be prepared to learn from students.

This study attempts to take a qualitative approach to a difficult question of what a medical students perceive about expected qualities of a good teacher .It focuses on how these perceptions change in a public sector medical schools where recourses are if not scarce but deficient in way that more and more doctors are fleeing away abroad. Basic science is the least option for a doctors due to non- paying nature and those doctors who are misfit in clinical side think of basic sciences as a final resort and teaching undergraduate as a piece of cake. We believe that the differences in the characteristics and qualities of excellent teachers, as perceived by medical students will help us to understand medical student's perspective that can give us an insight to increase the quality of teaching. It will provide an opportunity to observe excellent teachers which can lead to development of experienced faculty in basic sciences and development programs for basic science teachers to create an educational environment.

The objectives of this study were: (I) Toanalyse first year medical students' perceptions about the characteristics of an excellent teacher.(II) to identify the qualities that a teacher should possess in order to be an effective teacher . 
First Year Medical Student's Viewpoint Regarding Qualities of An Excellent ...

\section{Methodology}

The study was conducted within the premises of Allama Iqbal Medical College. We used a qualitative research methodology to identify the characteristics and qualities of an excellent teacher as perceived by first professional medical students. It was attempted to analyze the qualities and had an insight into processes and factors that helped us to identify what makes a teacher excellent in terms of teaching competency that can enhance the quality of medical education in medical schools. We started with a phenomenological approach to express the focus of medical student's subjective experiences and their interpretations of the excellent teacher.

\section{Participants}

From 650 first year and second year medical students, 25 students were selected as a purposive sample for the study.

\section{Instruments}

Personal qualities and lecturing characteristics were assessed using a semi-structured questionnaire comprising of open ended questions.

\section{Data Analysis}

Several analytic strategies were used such as Coding for both categorizing qualitative data and for describing the connotation and details of these categories, Memoing was done for recording the thoughts and ideas of the researcher involved in the research as they evolve throughout the study and Integrative diagrams and sessions were used to pull all of the details together. It was done to help make sense of the data with respect to the emerging theory and concepts regarding their perceptions and process during their academia. The diagrams used were simple cartoons that can act as summarizing devices.

\section{Results and Discussion}

Results were compared with the previous studies, such as those of Henzi, et al.(2005) and (Jahangiri, \& Mucciolo, 2008), the needs and desires of our students are similar in every culture and society. Our results were similar to that of Henzi, et al. (2005) regarding issues of 
supportiveness, and when compared to Jahangiri's et al. (2008), the request for experienced teachers and concerns about speaking style were equivalent. These findings do have a common themes with those of previous studies, but some characteristics are unique to universities in developing countries, and this may be a reason that the problems that public medical schools in developing countries may face similar problems but at a very basic stage. Under the theme of personal qualities, the two relatively unique sub themes, character and empathy towards medical students are recognized in similar studies, Jahangiri's et al. (2008)\&Henziet al. (2005).

Table 1

Personal qualities response categories and key words of students' perceptions of a university teacher

\begin{tabular}{|c|c|}
\hline $\begin{array}{l}\text { Personal } \\
\text { Qualities }\end{array}$ & Responses \\
\hline Character & Good moral character, Respect to students and conduct \\
\hline Experience & $\begin{array}{l}\text { Update Knowledge, clinical correlation and skills presentation, } \\
\text { Intelligently presentation, Easy and understandable delivery of lecture, } \\
\text { linking knowledge and its application }\end{array}$ \\
\hline Empathy & $\begin{array}{l}\text { Should be very empathetic, able to see from students' point of view } \\
\text { and know them personally, able to understand students' pressure of } \\
\text { other subjects' workload, and be sympathetic. } \\
\text { Give students due respect and appreciate their work in a positive way. }\end{array}$ \\
\hline Approachable & Should be very friendly, available and listening to their problems. \\
\hline
\end{tabular}

Table 2

Presentation skills response categories and key words of students' perceptions of a university teacher

\begin{tabular}{ll}
\hline $\begin{array}{l}\text { 1. Personal } \\
\text { Grooming }\end{array}$ & Responses \\
\hline $\begin{array}{l}\text { Attitude and dressing } \\
\text { Self confidence }\end{array}$ & $\begin{array}{l}\text { Professional attitude and well dressed } \\
\text { Self- confidence while delivering lecture, should be well } \\
\text { prepared and have excellent presentation skills, Should lead } \\
\text { the class while delivering lecture and ability to control the } \\
\text { boredom during lecture by using humor or interesting points } \\
\text { related to lectures. } \\
\text { Teacher should know difficulties students face especially } \\
\text { those away from home and having difficulties in studies, } \\
\text { friendly attitude }\end{array}$
\end{tabular}


First Year Medical Student's Viewpoint Regarding Qualities of An Excellent ...

2. Lecture preparation

Content

Content organization

liveliness

motivation

Dedicated

Content design

3. Lecture delivery Speaking style

Body language style

Interaction
Up to date and clear, explains difficult concepts at students' level and avoid jargon language, simplify difficult concept, systematic.

Lecture should be in flow and relevant to curriculum, orderly and exam oriented, clinically correlated, related to practical, according to objectives, starts from basic

Humor, pleasant smile, nice to see, evidently enjoys giving the presentation, active, , demonstrates liveliness in sharing knowledge

Make us inquisitive, makes an impression, appealing, relevant

Dedicated, devoted, maximum use of time, responsible

Diagrams, pictures, flow charts, videos, animation, diversity, attractiveness, visible power point slides, create support visuals that enhance the teaching without distracting from the lecture.

Simple and clear language, uniform medium of language (English), clear voice, loud but smooth voice, clarify in mother tongue if necessary, should be fluent, take time, slowly, normal pace, gives time to take notes, clear pronunciations, avoids complex, difficult words and rushing through slides and just reading power point, non-authoritarian,

Use of body movements and gesturers to support the presentation, should be calm and confident, and walking through class room instead of standing on one point., Negative- sitting while lecturing

Should spare time at the end of lecture for interaction and brief discussion with students to wrap things, always be in touch with whole class,

Negative- too many questions pointing to student embarrass, questioning, stress)

Four themes were inductively formed by integrating the subthemes. These themes were defined as personal qualities, personal grooming, lecture preparation and lecture delivery. The sub-theme speaking style under lecture delivery was high stressed by medical students and had the highest number of responses. Other popular subthemes included were content and content organization of a lecture, which fell under the theme of lecture preparation. Describing personal qualities of a teacher, most of the students laid stress on good moral character, giving due respect to students, and very experienced in terms of up to date knowledge but have a capability to deliver lecture in an 
easy and understandable way. Most important was to link this knowledge with practicable clinical applicability as we perceived that at this age students feel like to apply this knowledge to real patients, though they are not having a clinical rotation.

In sub theme of Empathy, students expect a teacher to understand their feelings as well as different social backgrounds of students.

"A teacher should be kind hearted and able to think like us, imagining that he/she was of same age and in the same situation."

"The teacher should understand students with varying capabilities and knowledge, so deal them accordingly."

"When the teacher shows compassion, we develop a desire to learn and the process is intense" as depicted by one of the student.

Approachability was also one of personal qualities, a student was looking for in a teacher and their perspective was that: " He should be friendly, available and listening to our problems" .The students appreciated teachers who were friendly, approachable, kind and empathetic.

"A teacher should be a person who tries to utilize the maximum time for disseminating knowledge to students."

"A teacher should not just present the content on a multimedia and just read it aloud and then finishes the lecture"

Student stress attitude and dressing in our personal traits theme and feel like that they should be dealt with a professional attitude and a teacher should be well dressed. While delivering a lecture, a teacher should be very confident and show impressive presentation skills .The students should feel that he is leading the whole class as a leader.

In teacher's teaching technique, most of students want updated and latest knowledge on subject but with easy and comprehensible approach, and less use of advanced terminology which they don't understand at this point. The lecture should be more pictorial, with diagrams, figures, flow charts, animation and videos.

In Lecture delivery, the students think that "An Effective presentation skills with command on voice, tone and accent makes a lecture effective and impressive, and this enhance their learning capabilities."

One possible causative factor for these responses is that data collection was conducted at a time when students were having professional examination and feel overload due to examination course and dissatisfied with their current performance. The public sector universities due to their massive student numbers (more than 340 in each class) and lack of recourses and draining of trained faculty in private 
medical sector have created doubts about the quality of education. Authorities in different countries have filled in gaps by hiring visiting teachers and clinicians, for example the measures taken by Sri Lanka Medical Council. On the contrary, the regulatory bodies in our medical faculty licensing are not looking keen to address this issue. Similar issues were found in other studies where due to new private medical school being established with government encouragement (Siribaddanaet al, 2012), the students were worried about allocation of resources. These findings show us a different perspective from students' point of view and their zest about obtaining medical education in a limited-resource setting and a public medical school.

While first year medical students are very enthusiastic regarding obtaining the best medical education they can, they are concerned about their role models at their university in terms of personal qualities and delivery of knowledge and feel dissatisfied when they are unable to see a role model in their lecture or feel discontent about the knowledge being delivered. Students studying in developing countries setting need their teachers to be empathetic, with high moral standards and always within their academic reach. The want to gain trust of their teachers and improve the quality of education they are receiving. Although other subthemes appear to be similar to what is reported by other studies and the observation of their verbatim expressions reveals that there are some concerns that should be dealt with more attention and detail regarding lecture quality, content and design.

An example of that would be; understanding the student problems and needs in terms of quality of education and transfer of knowledge that is similar in literature (Schönwetteret al., 2006) , expressed repeatedly, and emphasizes the need to understand the background and the social strata of the students, as in our setting more than $70 \%$ of student are females and more that $75 \%$ has a rural back ground mixed with Pakistani origin foreign graduates and those from different medium of English.

Students have constantly highlighted some crucial needs that are anticipated regarding content organization. (Table no: 2) These include up to date and clear knowledge, explaining difficult concepts at student level and avoiding jargon language, systematic, simplify difficult concepts .The contents should be delivered clinically and practically. They should be exam oriented as well as being included within the curriculum but at same time to be easy and understandable. The reality in basic sciences is harsh as at this time, many of the teachers don't choose their specialty by will. Some of them think that it is easy to get in and 
pursue their ultimate goal in their profession, others see it less stressful and flexible and initially they had little or no experience with medical teaching, curriculum development, or writing exams. This may be the reason for higher numbers of responses obtained for content delivery and organization sub-theme. These findings might trigger us to think about providing lectures with different experience levels, however, if this might not be feasible, these results can be effectively used in devising new faculty training procedures and provide incentives to those who opt teaching as a career especially in basic sciences, which will benefit our future generations. While the issue of speaking style is a universal issue, especially in Asian region, it needs a special attention. English language programmes ,focusing on speaking and writing need special attention due to their usefulness .The most important thing is how and what is being presented to the students and that defines the important quality of a teacher, especially in a country such as Pakistan, no matter he is experienced or not in his/ her field.

The medical students in Pakistan are taught in English, following British system of education but for most of them, there is a shift to language medium and have a vocal inability in English, thus becomes a barrier to learning. While in Pakistan, no school offers any English language course stressing on speaking and listening, it creates a gap between the teacher and a pupil, and hardly satisfy student's quest of knowledge. Moreover, the English language proficiency is also a need of teacher to continue improving his speaking skills, as students in our study have a very high expectations pertaining to delivery of a lecture. That is why speaking style had been discussed by most of the student(.Redding \& Walberg H.J. (2012).

Students expect teachers to use English language in their lectures in simple yet interesting way and teach at a slower pace, so that they can have a better understanding and retain the information for a longer period. Findings in this study stress the importance of a vocalist's who can deliver a lecture in simple way and facilitate that the student should be having a rapport and thus minimizing language barrier as depicted in other studies. (Nahar et al, 2010.)

It is suggested that students feel comfortable with multimedia while delivering lecture and the use of multimedia can reduce communication barriers as information is available. On the other hand, relying more on multimedia and delivering lectures solely on presented information reduce learning capabilities of students and they feel dissatisfied because they want to listen to the teacher's own way of communication rather than just reading a slide aloud. Visual aids can 
reduce verbal communication difficulties but it is important that they should be used in the appropriate manner. "A teacher should not just present the content on a multimedia, just read it aloud and then finishes the lecture"

Some students also underline the issues with unprepared lectures, half-hearted prepared slides and teachers merely reading the slides without any elaboration on the subject matter. Students idealize the teacher who has the ability to use a combination of teaching and learning media during their lectures, giving examples from his personal experience or real life scenarios. As in study by Dhaliwal (2007), this is a universal expectation and encourages the teacher to develop these skills right at the beginning of their careers (Dhaliwal, 2007).

In our study one important aspect we found out was student's expectation for respect and teacher being friendly while maintaining his dignity and good moral standing. This study just gives a glimpse of a need for the student-teacher faculty relationship in which they are comfortable and can approach a teacher in a friendly atmosphere.

One limitation of our study was that while interpreting qualitative data of our research, we were not able to conduct focus groups in order to achieve triangulation that could have limited our scope of understanding of the results.

\section{Conclusion}

It is concluded that students' expectations from their teachers are overwhelming in terms of personal qualities, although characteristics of teachers expected by the students are universal. Similar expectations from teachers are elaborated in other qualitative studies done in different countries with different socioeconomic status. This study for the first time has thrown some light on important qualities of teacher from student's perspective in a public medical school. Despite the fact that the medical students are more independent in their learning process, it is realized that the responsibilities of teachers in providing quality medical education need overcoming the short comings or conscious realization of the expectations by medical students. The students like those teachers who communicate to students actively and use problem based learning from real life situations and correlate it with clinical knowledge. They also consider that generating an interest in learning by linking knowledge and its application is an important quality of excellent teachers. 


\section{Ethical considerations}

Every possible effort was done to generate a congenial atmosphere and all the ethical constraints were duly addressed including permission from ethical review board of Allama Iqbal medical college and informed consent from medical students was obtained. Data collection was mainly by interview and at institution with the permission from the Dean of University. 
First Year Medical Student's Viewpoint Regarding Qualities of An Excellent ...

\section{References}

Axelrod, P. (2008). Student perspectives on good teaching: What history reveals: Academic matters: The journal of Higher Education. Retrieved January, 2016, from http://www.ocufa.on.ca/AM.pdf.

Dhaliwal, U. (2007). A prospective study of medical students' perspective of teaching learning media: reiterating the importance of feedback, Journal of the Indian Medical Association, 105, 11, 621-623.

Emery, C., Kramer, T., \&Tian, R. (2003). Return to academic standards: a critique of student evaluations of teaching effectiveness. Quality Assurance In Education, 11(1), 37-46. http://dx.doi.org/10.1108/09684880310462074

Henzi, D., Davis, E., Jasinevicius, R., Hendricson, W., Cintron, L. \& Isaacs, M., (2005) Appraisal of the dental school learning environment: the students' view, Journal of Dental Education, 69(10), 1137-1147.

Ho, M.T. \&Tani, M. (2007). What medical students value from their teachers, Australian Health Revolution, 31(3), 358-361.

Iskandar, I., Majzub, RM., and Mahmud, Z. (2009).Kecerdasanemosidankomitmenpekerjaandalamkalanganpensyarahun iversiti di Indonesia. Emotional quotient and work commitment among teachers at anIndonesianuniversity.Journal Pendidikan,34,173-186.

Ismail, A., Suh,YS.,Ajis, MN.,\&Dollah, NF. (2009). Relationship between occupational stress, emotional intelligence and job performance: An Empirical study in Malaysia," Theoretical and Applied Economics, 10, 316.

Jahangiri, L. \&Mucciolo, T.W., (2008). Characteristics of effective classroom teachers as identified by students and professionals: a qualitative study, Journal of Dental Education, 72(4), 484-493.

Maheux, B., Beaudoin, C., Berkson, L., Côté, L., Marchais, J.D. \& Jean, P. (2000). Medical faculty as humanistic physicians and teachers: the perceptions of students at innovative and traditional medical schools, Medical Education, 34(8), 630-634.

March, H.W.\& Roche, L. (1993).The use of student's evaluation and a structured intervention to enhance university teaching effectiveness. Education Research Journal, 30(1), 217- 251.

Nahar, N., Talukder, H.K., Khan, T.H., Mohammad, S.,\&Nargis, T. (2010).Students' Perception of Educational Environment of Medical 
Colleges in Bangladesh, Bangabandhu. Sheikh Mujib Medical University Journal, 3, 2-5.

Nelson, D. B., \& Low, G. R. (2003). Emotional intelligence: Achieving academic and career excellence. Upper Saddle River, NJ: Prentice Hall.

Ramsden, P. (1992). Learning to Teach in Higher

Education.doi:10.4324/9780203413937

Rayan, J. M. \&Harrison, P. (1995).The relationship between individual characteristics and the overall assessment of teaching effectiveness across different instructional contexts. Research in Higher education, 36 (5), 577 594.

Redding, S. \& Walberg H.J. (2012). Promoting Learning in Rural Schools Lincoln, Illinois: Centre on Innovation \& Improvement. http://www.adi.org/about/downloads/Promoting_Learning_in_Rural_Schoo ls.pdf

Sadwnik, L. The Art of Lecturing. Development and Educational Support. http://med.ubc.ca/files/2012/03/The_Art_of_Lecturing.pdf

Schönwetter, D.J., Lavigne, S., Mazurat, R.\&Nazarko, O. (2006) Students‘ Perceptions of Effective Classroom and Clinical Teaching in Dental and Dental Hygiene Education, Journal of Dental Education, 70,6.

Siribaddana, N., Agampodi, S. \&Siribaddana, S. (2012). Private medical education in Sri Lanka Indian Journal of Medical Ethics, 9(4), 269-271.

Squires, G. (1999).Teaching as a professional discipline. London, Falmer Press.

Walton, HJ. (1993). Proceedings of the World Sumiton Medical Education. Medical Education,28(1), 140-149.

Received on:09.01.2015

Revised on:05.06.2016

Accepted on:16.06.2016 